\title{
A ESCOLA E O ESTABELECIMENTO DA HIERARQUIA NA SOCIEDADE JAPONESA
}

\section{Resumo}

Wataru Kikuchi ${ }^{1}$

A hierarquia social é um componente importante para a compreensão da sociedade japonesa. $O$ presente trabalho pretende discutir a hierarquia na sociedade japonesa por meio da análise da escola, como uma das principais instituições de socialização. Para tanto, no primeiro momento, será empregado o método histórico na reconstituição da trajetória institucional das escolas do Japão, destacando-se os fatores de institucionalização da hierarquia, e por último, enfocará na estruturação e funcionamento da escola contemporânea, à luz do conceito de rotinização.

Palavras-chave: Sociedade japonesa. Escola. Hierarquia social. Militarismo. Rotinização.

\section{THE SCHOOL AND THE ESTABLISHMENT OF THE HIERARCHY IN THE JAPANESE SOCIETY}

\begin{abstract}
:
The social hierarchy is an important component for understanding Japanese society. The present paper intends to discuss the hierarchy in Japanese society through the analysis of the school, as one of the main institutions of socialization. For that, in the first moment, the historical method will be used in the reconstitution of the institutional trajectory of schools in Japan, highlighting the institutionalization factors of the hierarchy, and lastly, it will focus on the structure and operation of the contemporary school, in the light of the concept of routine.
\end{abstract}

Keywords: Japanese society. School. Social hierarchy. Militarism. Routinization.

\section{Introdução}

A escola, que neste artigo representa o sistema educacional japonês com destaque nos segundo e terceiro ciclos ${ }^{2}$, além do nível superior, será objeto de análise para compreender a hierarquia social do Japão.

A hierarquia constitui um fator social importante para a análise e compreensão da sociedade japonesa, podendo ser definida como sistema social que ordena os indivíduos numa escala de gradação, que se estende do topo à base, alocando-os internamente a um estrato (intraestrato) e na relação desse estrato com os demais (inter-estrato), também referência na distribuição de poderes e honrarias numa determinada sociedade ${ }^{3}$.

A centralidade da hierarquia no seio da sociedade japonesa já estava identificada nos primórdios do estabelecimento do que, posteriormente, seriam denominados Estudos Japoneses.

Na obra clássica O Crisântemo e a Espada, de 1946, Ruth Benedict afirmava que "a confiança japonesa na hierarquia é básica, dentro da sua noção global da relação do homem com o seu semelhante, da relação do homem para com o Estado" (2009, p. 43) e que conduta

\footnotetext{
${ }^{1}$ Professor da Área de Língua e Literatura Japonesa do Departamento de Letras Orientais da FFLCH-USP. É doutor em Sociologia pela mesma instituição. E-mail de contato: watarukikuchi@usp.br.

${ }^{2}$ Como será desenvolvido adiante, o sistema educacional japonês é estruturado em 6-3-3-4, respectivamente, Shôgakkô, primeiro ciclo ou "primário", Chûgakkô, segundo ciclo ou "ginásio", Kôkô, terceiro ciclo ou "ensino médio"e, por fim, Daigaku, ensino superior.

${ }^{3}$ A hierarquia social é pressuposta em várias teorias sociais, mas poucas fazem uma definição categórica dela. A definição aqui adotada inspira-se em Johnson (1997, p. 124).
} 
"assente com hierarquia é tão natural para eles [japoneses] como respirar" (op. cit., p.46). A autora prossegue afirmando que "não se trata, contudo, de um simples autoritarismo ocidental. Tanto os que exercem controle, como os que estão sob o controle dos outros, agem em conformidade com uma tradição diferente da nossa (...)", e elenca classe, sexo, idade, laços de família e "relações anteriores" como fatores de estabelecimento da hierarquia (ibid.).

A antropóloga social Nakane Chie é considerada precursora na análise da hierarquia social no Japão, com o modelo de sociedade vertical ou relação vertical da sociedade japonesa, publicado em diversos trabalhos nas décadas de 1960 e 70. Essa autora conferiu à hierarquia o status do princípio da estruturação da sociedade japonesa, ao identificá-la em todos os setores da sociedade, "mesmo entre aqueles que fazem parte do mesmo grupo e que possuem os mesmos atributos", pois "por algum meio são estabelecidas as "diferenças" e é definida uma hierarquia que "apresenta-se surpreendentemente minuciosa" (1967, p. 72, tradução nossa). Na sua análise, com ênfase nos locais de trabalho, a anterioridade no meio como fator definidor de hierarquia é destacada, como veremos adiante, com enfoque na escola.

Antes de passar para as considerações sobre a escola, convém observar que a centralidade da hierarquia é marcante ainda nos dias de hoje, nos estudos recentes sobre a sociedade japonesa (KIKUCHI, 2012; HOSHIBA, 2019; NAKANE, 2019).

Por outro turno, a escola tem sido uma das principais instituições de socialização da humanidade, ao longo da história.

Na concepção clássica, para Durkheim $(1999$, p. 6), educar é produzir o ser social, e a escola, ao lado da família, constitui um aparato de transmissão de valores e costumes para as gerações seguintes, processo esse importante para a reprodução e a continuidade da sociedade. Além da socialização, a escola possui também as funções de selecionar e de legitimar os estudantes que nela passam em diversas carreiras e futuras posições sociais (IWAI; KONDO, 2010, p. 6). Na primeira função, a de seleção, a escola tem a prerrogativa de instruir e preparar os aprendizes para a vida social e o mercado de trabalho ${ }^{4}$, e os legitima a essas carreiras e posições sociais, por meio da emissão de diplomas e certificados para os formados. Apesar da importância dessas atribuições da escola, o presente trabalho dará enfoque à primeira função, de socialização.

A escola, pela sua natureza, pressupõe hierarquia interna. Há sempre uma desigualdade de posição entre aquele que ensina (mestre) e aquele que aprende (aprendiz). Mas afora a conscientização dessa hierarquia básica, a tese aqui desenvolvida é a de que haveria alguma outra forma de transmitir, de compelir os aprendizes a internalizem a noção de hierarquia nas escolas japonesas. Para discutir essa questão, é necessário voltar para o passado, e a análise tratará, inicialmente, do percurso de estabelecimento das escolas no Japão ao longo da história. Em seguida, considerando a escola na atualidade como resultado desse processo histórico, serão focalizados a sua estruturação e o fator anterioridade no meio, que se estabelece na consciência dos estudantes desde cedo.

Para o efeito de transcrever os termos da língua japonesa, será empregado o padrão internacionalmente reconhecido, com exceção do uso do acento circunflexo para indicar o alongamento da sílaba, como em gakkô (dever ser lido "gakkoo").

\footnotetext{
${ }^{4}$ Convém observar que essa discussão envolve questões como meritocracia e igualdade de oportunidade de estudo, de acesso à educação. Para Bourdieu (2008), a escola contribui para reproduzir a desigualdade social.
} 


\section{A escola japonesa: um breve histórico}

O objetivo dessa seção é fazer um breve histórico da escola do Japão, na tentativa de caracterizá-la na sua formação, como instituição que forma a consciência de hierarquia.

Para efeito analítico, os períodos históricos serão divididos em Antiguidade, Xogunatos, Eras Moderna e Contemporânea, privilegiando a formação institucional tanto no nível do Estado quanto na sociedade civil.

\subsection{Antiguidade}

A Antiguidade, que se estende do século III ao XII ${ }^{5}$, compreende a fase da formação do Estado japonês, com o estabelecimento do aparato governamental tendo como modelo o chamado Sistema Ritsuryô ou Estado Legista, importado da China da época.

Segundo os registros históricos, a primeira instituição educacional japonesa teria sido o chamado Daigaku, órgão de formação dos oficiais do governo central. Originado na segunda metade do séc. VII, vinculado ao Ministério de Recursos Humanos e Cerimonial, Shikibushô, e consolidado ao longo do século VIII, essa instituição formava os futuros funcionários dessas repartições, que eram promovidos mediante concursos, lecionando Direito, Matemática, Confucionismo, Letras Clássicas Chinesas etc., na concepção atual de denominação das disciplinas. Cada matéria tinha um mestre ministrante e dois auxiliares de ensino, que lecionavam para cerca de quatrocentos alunos, em regime de internato (NIHONSHI KOJITEN HENSHU IINKAI, 2016, p. 576). Entre os sécs. VII e IX, nos territórios regionais, a instituição Daigaku teve versão similar, os chamados Kokugaku, com estrutura semelhante de ensino e cerca de cento e quarenta alunos por unidade. Na prática, possuía caráter de sucursal do Daigaku, uma vez que muitas vezes, os mestres eram enviados pelo governo central (NIHONSHI KOJITEN HENSHU IINKAI, 2016, p. 341).

É importante notar que, nessas escolas, tinham prioridade no ingresso filhos de nobres até o $5^{\circ}$ grau $^{6}$ ou de oficiais na ativa, no caso do Daigaku, e filhos de governantes de territórios, no caso do Kokugaku (SATO, M. et alii, 2008, p. 86). Na prática, isso se tornava uma barreira de acesso para os membros dos demais estratos, contribuindo para a manutenção do privilégio das elites aristocráticas.

No período Heian (794-1192), surge outra vertente importante de instituições de ensino, ligada aos templos budistas, na formação de monges. Um dos expoentes foi o monge Saicho (767-822), fundador da corrente Tendai, que, após o regresso da viagem de estudos na China, em 805 , teria começado a formação de monges $^{7}$ por volta de 818 . Suas práticas de ensino foram consolidadas e continuadas no templo Enryaku, de Hieizan, na divisa entre Quioto e Shiga, existente até hoje.

Aproximadamente duas décadas depois, o monge Kukai (774-835), fundador da corrente Shingon, teria inaugurado em Quioto Shugeishuchiin, uma instituição que poderia ser

\footnotetext{
${ }^{5}$ Em termos de periodização comumente adotada, compreendem os períodos Yamato (séc. III a VII), Nara (710794) e Heian (794-1192).

${ }^{6}$ O Código Ritsuryô estabelecia quatorze graus nobiliárquicos, do primeiro ao sétimo graus. Desses, do primeiro ao quinto grau havia duas graduações internas e no sexto e sétimo, quatro cada. Nessa hierarquização, eram considerados de fato nobres aqueles detentores a partir do quinto grau, e para ocupar os principais cargos do governo, o pré-requisito era que se possuísse do terceiro para cima.

${ }^{7}$ Seus fundamentos podem ser encontrados em Sange Gakushôshiki, publicado por volta de 818.
} 
considerada pioneira, por ensinar principalmente o budismo e o confucionismo para qualquer interessado, sem se restringir aos nobres e monges (TAKAGI, 2009). Suas atividades teriam sido encerradas em 845, mas a formação dos monges teve prosseguimento nos templos, notadamente em Kongôbu, de Kôyasan, em Wakayama.

\subsection{Xogunatos}

Xogunato é a denominação do sistema de governo comandado por estrato guerreiro, os bushi ou samurais, que se sucederam ao longo dos séculos XII a XIX.

O primeiro deles, o xogunato de Kamakura (1192-1333), não registrou nenhuma instituição formal de ensino, sendo a educação realizada dentro do lar, cada qual de acordo com o estrato social pertencente. Por exemplo, o estrato guerreiro ensinava para seus filhos princípios de conduta como lealdade à própria família e ao clã, valores como honradez, bravura, honestidade e frugalidade, além de artes de manejo de armas e de cavalaria (SATO, et alii, 2008, p. 147).

No segundo xogunato, de Muromachi (1333-1573), destaca-se o Ashikaga Gakkô, que teria sido fundada anteriormente e reconstruído por volta de 1432. Era instituição superior de formação de monges, mas também acessível para samurais de todo o arquipélago, que se reuniam para estudar sobre budismo e confucionismo. Situava-se na atual província de Tochigi, foi considerada "Universidade da região Bandôn" pelos jesuítas no séc. XVI, e ao longo do tempo perdeu sua importância, mas existiu até o ano de 1872, como escola regional (KAWASE, 1974).

No terceiro xogunato, de Edo (1603-1868), ocorreu maior domínio político-social por parte dos guerreiros e estruturação abrangente do governo, condições estas que permitiram a longevidade do regime. Como consequência, o aparato educacional também apresentou contornos mais elaborados. Para formação de seus dirigentes, o xogunato construiu Shoheizaka Gakumonjo, centro educacional de instrução neoconfucionista ${ }^{9}$. Funcionou na sede do regime em Edo ${ }^{10}$, de 1797 a 1870 (SATO, M. et al., 2008, p. 306 e 337).

No plano regional, cada unidade administrativa possuía escolas para instrução de filhos de guerreiros, os Hankô. As primeiras unidades teriam sido inauguradas nas décadas iniciais do séc. XVIII, e no final do período Edo, contabilizavam em torno de trezentas. Além do neoconfucionistmo, replicando Shoheizaka Gakumonjo como modelo, essas escolas ensinavam Letras Clássicas Japonesa e Chinesa, Matemática, Caligrafia, entre outras matérias (REKISHI KYOIKUSHA KYOGIKAI, 2012, p. 285).

A necessidade de educar os filhos de outros estratos, principalmente dos citadinos, fez com que surgissem, no início do século XIX, instituições privadas denominadas Terakoya ${ }^{11}$. Fundados por monges, sacerdotes xintoístas, comerciantes abastados, oficiais da administração regional e ainda guerreiros independentes, reuniam-se vinte a trinta crianças de seis a treze anos para ensinar a ler e escrever, a manipular o ábaco, além de conhecimentos para a vida e

\footnotetext{
${ }^{8}$ Atual região Kantô, Tóquio e províncias adjacentes.

${ }^{9}$ Da escola Shushigaku, que segue os ensinamentos do pensador chinês Zhu Xi (1130-1200).

${ }^{10}$ Atual Tóquio, cidade que se tornou oficialmente capital do Japão em 1869.

${ }^{11}$ Terakoya significa literalmente "templo-cabana", por ter sido inicialmente aberto por monges, em templos budistas. À medida que mestres de outros estratos surgiram, passaram a ocupar espaços correspondentes como cantos de estabelecimentos comerciais e casas. Das grandes metrópoles, como Edo e Osaka, se expandiram para cidades menores até a zona rural, no final do período.
} 
princípios morais baseados principalmente no confucionismo. No final do século, estimam-se em torno de 15 mil estabelecimentos desse tipo existentes em todo o território, e que cerca de $20 \%$ da população de citadinos e camponeses fossem educados, mostrando alto grau de instrução para o período, mesmo comparados com outros países ocidentais (MOCHIZUKI; HARIMOTO; OKAMYO, 2010, p. 49).

\subsection{Era Moderna}

As escolas do Japão, tal qual conhecemos hoje, têm suas origens nas instituições de ensino que surgiram juntamente com o Estado moderno, no final do século XIX. Após o fim do xogunato de Edo que culmina na Restauração Meiji (1868), os dirigentes do novo regime construíram um Estado centralizado em torno da figura do imperador Meiji (1852-1912) e as grandes reformas e medidas foram executadas em seu nome. Entre essas medidas, estava o estabelecimento do moderno sistema educacional, para formar súditos do grande império em construção.

\subsubsection{Estabelecimento do sistema educacional}

Dentro desse contexto, a primeira medida de impacto tomada na área educacional foi a criação do Monbushô, Ministério da Educação, em 1871, tendo como objetivo instalar o sistema educacional nos moldes do Ocidente. No ano seguinte, esse ministério instituiu o Gakusei, "Sistema Educacional", que promovia o acesso à educação a todas as crianças, independentemente de origem social. Foram inauguradas mais de 20 mil escolas do primeiro ciclo (Shogakkô), em muitos casos aproveitando a estrutura já existente dos Terakoya. Esse ciclo foi dividido em duas fases, com duração de quatro anos, totalizando oito, e o ingresso era permitido a partir de seis anos. O segundo ciclo (Chûgakkô) também era dividido em duas fases com duração de três anos, totalizando seis. Em 1877, foi inaugurada a Universidade Imperial de Tóquio, Tokyo Teikoku Daigaku, resultante da fusão da Tokyo Kaisei Gakkô, escola de idiomas e de conhecimentos ocidentais, e Tokyo Igakkô, escola de medicina, ambas inauguradas no início do período Meiji.

Embora tivesse atingindo, em 1875, o ingresso de 50\% de meninos e 18,7\% das meninas em idade escolar, esse sistema educacional encontrou forte resistência, principalmente na zona rural, pois acarretava custos extras para as famílias, além de reduzir o contingente de mão de obra, meninos que, até então, contribuíam com o trabalho ${ }^{12}$ (SATO et alii, 2008, p. 337). A meta inicial, de dividir o Japão em oito grandes blocos, culminando na construção de universidades em cada um deles, era excessivamente idealista e distante da realidade (SATO et alii, 2008, p. 337).

Diante desse quadro, o governo de Meiji promulgou, em 1879, a Lei da Educação, Kyôikurei. Em linhas gerais, essa lei cancelou a meta ambiciosa do Gakusei e promoveu a descentralização da instalação das escolas primárias, delegando essa competência às cidades e vilarejos, além de lhes atribuir a liberdade para estabelecer a duração de cada ciclo letivo, podendo variar de um ano e quatro meses a quatro anos. Mas a alta evasão escolar, associada à inconveniência de ter vários períodos letivos em vigor, fez o governo reformar a própria lei em 1880 e, ao longo dessa década, outras leis foram aprovadas com o intuito de aperfeiçoar o

\footnotetext{
${ }^{12}$ Por esse motivo, muitos pais não seguiam essa determinação do governo e, muitas vezes, as autoridades até recorriam à força policial para obrigá-los a liberar os filhos para a escola (NARUSAWA, 2011, p. 112).
} 
sistema, até que, em 1900, o ensino obrigatório gratuito de quatro anos foi estabelecido. Em 1907, o tempo escolar do primário foi estendido a seis anos e, no final da década, havia mais de 25 mil escolas primárias, com 98\% de crianças na idade escolar frequentando essas instituições (SATO et alii, 2008, p. 394).

Constata-se, dessa forma, que nos primórdios da modernização da sociedade japonesa, a instalação do sistema escolar foi realizada por avanços e recuos. Mas a definitiva transformação aconteceu a partir de 1890, quando foi publicada a "Mensagem Imperial sobre a Educação", Kyôikuchokugo, estabelecendo as diretrizes da educação do Império Japonês. O conteúdo dessa Mensagem foi de fundamental importância para a compreensão da educação na fase anterior e durante a Segunda Guerra Mundial, que deixou consequências duradouras, na forma de reação a esses princípios no pós-guerra.

\subsubsection{A escola do Império Japonês}

A "Mensagem Imperial sobre a Educação", em vigor a partir de 1890, estabeleceu os princípios do Grande Império Japonês como a base da educação do Japão, tendo como ponto central a lealdade do povo ao imperador, este considerado pai e corporificação da virtude da nação, e formação de súditos eficazes e fiéis a esse princípio, dispostos a oferecer o "corpo e a alma" quando convocado pelo império (UZAWA, 1998, p. 174). Essa mensagem foi distribuída para todas as escolas do território e era obrigação da direção promover a sua recitação em ocasiões solenes e reuniões matinais com os alunos (NIHONSHI KOJITEN HENSHU IINKAI, 2016, p. 244). As fotografias do imperador e da imperatriz Meiji, denominadas goshin'ei, também passaram a ser reverenciadas e distribuídas para as escolas e, na década de 1930, todas as instituições de ensino do país as possuíam nas suas dependências (HIROOKA, 2007, p. 135).

Esse processo de exaltação da figura do imperador e, por meio dela, de formar cidadãos obedientes e soldados dispostos a lutar para o império, teve um componente instrumentalmetodológico importante, que foi a introdução dos princípios de treinamento militar na educação. Na escola de formação de professores, Shihan Gakkô, criada em 1872 e reorganizada em 1886, num regime de internato inspirado na academia militar, foram implantadas rigorosas normas de convívio em grupo e a obrigação de treinamento físico, para que os alunos assimilassem e, depois na condição de professores formados, as aplicassem cada qual na sua escola (NARUSAWA, 2011, p. 115). O castigo físico era constante, como componente desse "treinamento". Mesmo após a proibição por lei, em 1879, de punir os alunos com castigo físico, foi regra constante nesse período (NARUSAWA, 2011, p. 116).

A ascensão dos militares ao governo e a eclosão da Guerra do Pacífico, em 1941, trouxeram como consequência a formalização e o fortalecimento da militarização das escolas do Japão. Nesse ano, pela "Lei da Escola do Povo", Kokumingakkôrei, foi instaurada a chamada "Escola do Povo", Kokumingakkô, em substituição à escola do primeiro ciclo, Shôgakkô. Segundo seu artigo primeiro, o objetivo da escola passava a ser "realizar a educação e formação básica do povo seguindo as diretrizes do império" (HIROOKA, 2007, p. 152). Desde 1938, já havia a convocação dos estudantes para trabalhar nas fábricas de confecção de armamentos e outros utensílios para a guerra e, a partir de 1941, até trinta dias letivos passaram a ser convertidos para tal finalidade. A partir de 1943, estudantes do sexo masculino acima de vinte anos foram convocados como soldados para a frente de batalha.

A deterioração das posições japonesas na guerra e a concentração dos ataques ao seu 
território, em 1944, afetaram drasticamente as condições de ensino nas escolas. A partir de abril de 1945, qualquer atividade de ensino ficou inviabilizada e, oficialmente, todas as aulas do segundo e do terceiro ciclos foram suspensas. Após a rendição do Japão, em setembro, com a ocupação dos aliados, o gabinete formado por Higashikuninomiya Naruhiko decretou a retomada das aulas, duas semanas após o término da guerra (HIROOKA, 2007, p.156).

\subsection{Era Contemporânea: retomada e a nova educação no pós-guerra}

A política de ocupação do Japão, conduzida pelos EUA, tinha como princípio abolir os pilares do imperialismo japonês, a começar pela ideologia constituída tendo como figura central o imperador. O expurgo foi realizado em várias frentes e o setor educacional não poderia passar incólume.

Foi nesse contexto que, em 31 de março de 1947, entrou em vigor a Lei Orgânica da Educação, Kyôiku Kihon'hô. Elaborada sob a supervisão dos americanos, essa lei enfatizou os princípios democráticos, sendo seus pilares a liberdade, a igualdade de direitos e a consciência da individualidade (NIHONSHI KOJITEN HENSHU IINKAI, 2016, p. 243). Como diretrizes da política educacional, essa lei determinou a igualdade na oportunidade de acesso à educação, ensino obrigatório de nove anos e a instalação de escolas mistas de alunos e alunas (HIROOKA, 2007, p. 158).

Como complementação da Lei Orgânica da Educação, na mesma data, foi promulgada a Lei da Educação Escolar, Gakkô Kyôikuhô, que estipulou os diretrizes da organização das escolas no Japão. Por essa lei, foi instituído o chamado "sistema 6-3-3-4": seis anos no primeiro ciclo, Shôgakkô; três anos no segundo ciclo, Chûggakkô, três anos no terceiro ciclo, Kôtôgakkô e quatro anos no ensino superior, Daigaku. A implantação de cada ciclo foi, no entanto, escalonada: primeiro e segundo ciclos no mesmo ano, terceiro ciclo no ano seguinte, e o ensino superior em 1949. Também em 1949, foram instituídas universidades de curta duração, Tanki Daigaku $^{13}$, e, em 1961, Escolas Técnicas, do terceiro ciclo (NIHONSHI KOJITEN HENSHU IINKAI, 2016, p. 182).

A “Mensagem Imperial sobre a Educação", na prática sem nenhum efeito após essas reformas, foi abolida formalmente pelo Congresso em junho de 1948.

A Lei Orgânica da Educação ditou a política educacional do Japão no pós-guerra até a atualidade, até ser substituída por uma nova lei de mesmo nome, em 2006, que em termos de conteúdo reproduz essencialmente a anterior, acrescentando as concepções gerais como espírito público, educação continuada e preservação do meio ambiente (HIROOKA, 2007, p. 174).

\section{A escola e consciência hierárquica: regras e castigo físico}

A forte reação no pós-guerra contra a ideologia dominante e os consequentes princípios educacionais da fase imperialista, conforme foi visto na seção anterior, sugeriam que a escola no Japão se tornasse uma instituição renovadora e igualitária, no sentido de fomentar a igualdade e não a relação hierárquica. Mas a realidade é exatamente oposta e é na escola que os japoneses adquirem a noção de hierarquia ou é na fase de permanência nela que a consciência hierárquica é despertada.

A explicação para esse fato deve ser buscada na própria constituição da escola e no

\footnotetext{
${ }^{13}$ São universidades que oferecem cursos com duração de dois anos, de conteúdo profissionalizante.
} 
funcionamento, nos moldes como foi consolidada nas últimas sete décadas. E, paradoxalmente, a constatação é a de que muitos traços do militarism ${ }^{14}$ acabaram prevalecendo, velados ou não, conscientemente ou não dos dirigentes do seu tempo. E isso pode ter sido intencional, pelo menos no início, uma vez que, mesmo no pós-guerra, ao contrário do que se imagina, muitos dirigentes da escola tinham fortes vínculos com o setor militar, a maioria dos diretores da escola primária era militar reformado (WOLFEREN, 1999, p. 217).

Observando o controle que a escola exerce sobre os alunos, ela tem regulamentos que determinam o modo de se vestir e de se apresentar: todos são uniformizados, há tipos do corte de cabelo permitidos, restrições sobre tingimento e maquiagem, os adereços que podem ser usados, o comprimento da saia que as alunas podem vestir, medido a partir do joelho etc. ${ }^{15}$

O controle da escola se estende até quando o aluno se retira das suas dependências, por exemplo, algumas escolas proíbem que seus alunos venham de bicicleta, outras determinam que o estudante vá embora direto para casa e que o celular deve permanecer desligado até a estação de trem ou metrô próxima (KOKUGAKUIN, 2020). A rigor, isso atende à expectativa da própria sociedade, que atribui à escola a tarefa de fiscalizar a conduta dos estudantes; mesmo estando fora dos seus domínios, na condição de alunos, eles são sempre relacionados com a escola $^{16}$.

Além de todas essas regras detalhadas, que fazem alusão ao militarismo implantado na fase imperialista, cabe ressaltar que todas as escolas japonesas têm o seu hino e a sua bandeira. Isso faz imaginar uma escola como um batalhão dividido em companhias, que seriam as séries, com características internas homogêneas, uma vez que nesse sistema, não há reprovação nos dois primeiros ciclos. Isso faz com que todas as séries e classes escolares sejam constituídas por alunos de mesma idade ${ }^{17}$ sendo as atividades escolares organizadas conforme a idade (MOCHIZUKI et alii, 2010, p. 60).

Por fim, mesmo o castigo físico, traço marcante do militarismo, ainda está presente nas escolas japonesas. Segundo os dados do governo japonês, em 2018, 578 professores de escolas públicas do Japão foram punidos ou advertidos por praticar castigo físico (MONKASHO, 2020). Há uma tradição arraigada de conceber o castigo físico como benéfico para a educação e o fortalecimento espiritual do aluno $^{18}$, herança da fase militar (KUROKAWA, 2012, p. 116), e a sua prática pode ser muito mais frequente do que imaginamos ou que as estatísticas demonstram (TOTSUKA, 2006; OGI, 2006).

\footnotetext{
${ }^{14} \mathrm{O}$ militarismo será empregado no sentido de penetração e predomínio da ideologia e das diretrizes próprias dos militares em amplas esferas da sociedade (BOBBIO; MATTEUCCI, 1992, p. 748), no contexto do Grande Império Japonês.

${ }^{15}$ Por exemplo, no regulamento do Colégio Kokugakuin, um dos mais tradicionais de Tóquio, consta que os alunos devem seguir rigorosamente a norma escolar e que há inspeção periódica para verificar o seu cumprimento (KOKUGAKUIN, 2020).

${ }^{16}$ Para ilustrar, quando um aluno comete suicídio, é o diretor da escola que ele frequentava que aparece nos meios de comunicação como responsável, e muitas vezes, dele é cobrada alguma responsabilidade.

${ }^{17}$ É necessário lembrar que o ano letivo japonês se inicia em abril e termina em março do ano seguinte. Portanto, as crianças que nasceram nos meses de janeiro a março são incorporadas na série do ano anterior.

${ }^{18} \mathrm{Na}$ legislação vigente, a definição de castigo físico é aquele que "traz danos ao corpo", devendo ser avaliado caso a caso, mas medidas como deixar o aluno de pé dentro da sala, obrigar a permanecer na escola após o término da aula, assim como atribuir tarefas como faxina, não se enquadram no caso (KUROKAWA, 2012, p. 117).
} 


\section{A escola e consciência hierárquica: ordem de ingresso}

Conforme aludido anteriormente, na sociedade japonesa, o princípio de antiguidade ou a ordem de ingresso no meio, em que aqueles que chegaram antes, senpai ou "veteranos", têm prioridade, preferência e gozam de direitos e privilégios sobre aqueles que ingressaram posteriormente, kôhai ou "novatos", constitui um dos principais fatores de determinação da hierarquia social.

No caso da escola, essa ordem fica evidente, pois como foi explanado na seção anterior, os alunos são agrupados conforme a idade e avançam nas séries, de forma homogênea. Desde cedo, os estudantes aprendem a tratar devidamente os veteranos, colocando-se no seu devido lugar.

Outro aspecto que marca a vida escolar é a existência da atividade denominada "atividade de clube", kurabukatsudô, ou "atividade de departamento", bukatsu. Essas atividades são extracurriculares ${ }^{19}$ e existem em todas as escolas do segundo e terceiro ciclo do Japão ${ }^{20}$, divididas em setores, com preponderância do esporte coletivo (baseball, vôlei, futebol, basquete etc.), esporte individual (atletismo, natação, alpinismo etc.), artes marciais (karatê, judô, aikidô, kendô etc.), além de artes tradicionais como caligrafia, cerimônia do chá, ikebana e outras.

A noção da hierarquia baseada na ordem de ingresso é cultivada e transmitida nesses "clubes" ou "departamentos", conjugada aos valores como realização pessoal, união e pertencimento pessoal (KIKUCHI, 2012, p. 170-72).

Uma vez estabelecida, a relação veterano e novato das atividades de clube perdura por resto da vida, constituindo um componente importante dos japoneses como ser social (WHANG, 2007, p. 158).

\section{Considerações finais}

Qualquer japonês em idade escolar passa a maior parte do seu tempo na escola. Além dos dois primeiros ciclos obrigatórios, atualmente, $97,8 \%$ dos estudantes ingressam no terceiro ciclo do sistema educacional japonês ${ }^{21}$ (TSUCHIYA, 2011, p. 74). Isso evidencia a importância da escola na formação dos jovens, contando ainda que no Japão a escola é de período integral, o aluno permanece quase o dia inteiro, pois ali estuda, almoça, faz faxina e ainda participa das atividades extracurriculares, conforme visto na seção anterior.

Nesse sentido, é inegável o peso da escola na formação do japonês, os valores que lhe são transmitidos, as normas sociais que vão se internalizando, conscientemente ou não, o indivíduo japonês dificilmente consegue ficar alheio às relações sociais que ali se estabelecem.

Esse dado remete para a questão da coerção associada à sanção, que, conforme Giddens, tem relação com a autoridade e o poder. Isto porque, segundo esse autor, os aspectos coercitivos do poder revelam-se na forma de "sanções de vários tipos, indo desde a aplicação direta da

\footnotetext{
${ }^{19}$ Foram introduzidas no período Meiji, tendo como finalidade "mais do que desenvolver o físico dos estudantes, para aprimorar o aspecto espiritual e de virtude" (Nakamura, 2009, p. 16).

${ }^{20}$ A participação nessas atividades não é obrigatória na maioria das escolas, mas, segundo Nakamura, na média, cerca de $50 \%$ dos alunos de uma escola participam de algum departamento ou clube e $30 \%$ deles são de setores esportivos (2009, p. 29). Os alunos do terceiro ano tendem a não participar dessas atividades, pois estão na fase de preparação para o vestibular.

${ }^{21}$ A taxa de ingresso no ensino superior é de 52,9\% (TSUCHIYA, 2011, p. 75).
} 
força ou violência ou a ameaça disso, até a expressão moderada de desaprovação." (1989, p.143). No caso da escola japonesa, conforme a descrição feita ao longo do trabalho, esse tipo de coerção é inerente à própria instituição, seja no aspecto "militar", no constrangimento que a escola impõe aos alunos que não "seguem na linha", quanto no relacionamento que se estabelece entre o professor e o aluno e entre os alunos veteranos e novatos.

Na síntese que se fez da história da instituição educacional no Japão, observou-se que, por longo período, a educação era privilégio de monges, nobres, guerreiros e uma pequena parcela de comerciantes e se estendeu para a população em geral somente no século XIX. Esse último período foi marcado pelo domínio dos guerreiros, com forte noção de hierarquia. A modernização nos moldes do Ocidente, promovida pelos dissidentes do antigo regime, criou um Estado centralizado cuja marca na política educacional foi a adoção do militarismo, com forte orientação ideológica, exercendo o papel de formação dos súditos leais ao império. A libertação dessa ideologia, no pós-guerra, e a estruturação da nova política educacional não permitiram desvencilhar-se completamente do militarismo na escola do Japão.

Dessa forma, a hierarquia está presente no cotidiano do indivíduo japonês desde a tenra idade, em outras palavras, está "rotinizada", conforme Giddens (1989, p. XIX), algo feito habitualmente como um elemento básico da atividade social cotidiana, desde sempre. E isso cria a visão de mundo dos japoneses, pois a "rotinização é vital para os mecanismos psicológicos por meio dos quais um senso de confiança ou segurança ontológica é sustentado nas atividades cotidianas da vida social." (1989, p. XIX).

Por fim, cabe ressaltar que não está nos propósitos deste trabalho criticar a hierarquização da sociedade japonesa ou destacar o aspecto de submissão, pois, ao mesmo tempo em que é coercitiva, é ela que fornece os recursos para levar adiante a vida social dos japoneses.

Levar a vida adiante nesse contexto significa "conformar-se", sem necessariamente "tornar-se submisso", podendo ser interpretado como "aceitação consciente" ou, conforme Giddens, "até mesmo a aceitação "voluntária" das relações de poder mais amplas nas quais ele se insere" (1989, p. 144).

Isso também está relacionado com a capacidade de "ativar ou executar" as "prerrogativas de papel”, nos termos de Giddens (1989, p.67), ou "expectativa de papel”, na terminologia de Goffman (1975), e que vai ao encontro da afirmação de Nakane, no que ela se expressa como "compor":

Na realidade, uma relação interpessoal importante que a autora pretende [eu pretendo] indicar pelo termo relação vertical não é o inferior se subordinar ao superior, mas se compor de maneira adequada. Além disso, [o importante] é não esquecer do decoro da hierarquia, perante os de fora. (1978, p. 86, tradução nossa).

Dessa forma, é possível presumir que o indivíduo japonês se submete à relação hierárquica porque a vida social exige isso ou que faz parte da sua expectativa de papel. Nesse sentido, a sanção que muitas vezes o indivíduo japonês sofre é por "não saber compor", nos termos da Nakane, ou, em outras palavras, por não atender à “expectativa de papel”.

Então, no caso da escola japonesa contemporânea, pode se afirmar que ela exerce perfeitamente a dupla função que lhe é incumbida: instruir e preparar os jovens para a vida social. 


\section{Referências bibliográficas}

BOBBIO, Norberto; MATTEUCCI, Nicola. Dicionário de Política. 4a. ed. Brasília, DF: Ed. Universidade de Brasília, 1992.

BOURDIEU, Pierre. A Distinção: crítica social do julgamento. São Paulo: EDUSP; Porto Alegre, RS: Zouk, 2008.

DURKHEIM, Émile. As regras do método sociológico. $2^{\mathrm{a}}$. ed. São Paulo: Martins Fontes, 1999. GIDDENS, Anthony. A constituição da sociedade. São Paulo: Martins Fontes, 1989 [1984].

GOFFMAN, Erving. A representação do Eu na vida cotidiana. Petrópolis: Vozes, 1975.

HIROOKA, Yoshiyuki. Kyôiku no Seido to Rekishi (O Sistema Educacional e História). Quioto: Mineruva Shobo, 2007.

HOSHIBA, Tatsuo. "Nihon Bunkaron" wo Koete (Avançando além das Teorias da Cultura Japonesa). Tóquio: Kadensha, 2019.

IWAI, H.; KONDO, H. Gendai Kyôiku Shakaigaku (Sociologia da Educação Contemporânea). Tóquio: Yuhikaku, 2010.

JOHNSON, Allan G. Dicionário de Sociologia: guia prático da linguagem sociológica. Rio de Janeiro: Jorge Zahar, 1997.

KAWASE, Kazuma. Ashikagagakkô no Kenkŷ̂ (Estudo sobre a Escola Ashikaga). Tóquio: Kodansha, 1974.

KIKUCHI, Wataru. Relações hierárquicas do Japão contemporâneo: um estudo da consciência de hierarquia na sociedade japonesa. 2012. 221p. Tese (Doutorado em Ciência, Sociologia) Faculdade de Filosofia, Letras e Ciências Humanas da Universidade de São Paulo, São Paulo.

KOKUGAKUIN: site. Disponível em: <https://www.kokugakuin.ed.jp/admission/qa/>. Acesso em: 11 dez. 2020.

KUROKAWA, Masako. Gakkô ni okeru Taibatsu to Hô (O castigo físico na escola e a lei). In: SAKATA, Takashi. Gakkô to Hô (A Escola e a Lei). Tóquio: Hoso Daigaku Kyoiku Shinkokai, 2012. p. 107-118.

MOCHIZUKI, S.; HARIMOTO, H.; OKAMYO H. (Orgs.). Nihon no Kyôiku o Kangaeru Genjô to Tembô (Reflexões sobre a Educação do Japão: realidade e perspectivas). Tóquio: Gakubunsha, 2010.

MONKASHO, Ministry of Education, Culture, Sports, Science and Technology-Japan: site. Disponível em: <https://www.mext.go.jp/a_menu/shotou/jinji/1411820_00001.htm>. Acesso em: 12 dez. 2020.

NAKAMURA, Toshio. Kurabu wo Toinaosu (Rediscutindo o "Clube"). In: NAKANISHI, T.; MORI, T. Nakamura Toshio Chosakushû Dai4kan Bukatsu-Kuraburon (Coleção Obras de Nakamura Toshio Vol.4: discussão sobre a atividade de departamentos e "clubes"). Tóquio: Sobunkikaku, 2009.

NAKANE, Chie. Tateshakaino Ningenkankei (As Relações Pessoais na Sociedade Vertical). Tóquio: Kôdansha, 1967.

NAKANE, Chie. Tateshakaito Gendai Nihon (A Sociedade Vertical e o Japão Atual). Tóquio: Kôdansha, 2019. 
NARUSAWA, Akira. Gendai Nihon no Shakai Chitsujo - rekishiteki kigen o motomete (A Ordem Social do Japão Contemporâneo: na busca das origens históricas). Tóquio: Iwanami Shoten, 2011.

NIHONSHI KOJITEN HENSHU IINKAI (org.). Yamakawa Nihonshi Shôjiten (Pequeno Dicionário Yamakawa de História do Japão). Tóquio: Yamakawa Shuppansha, 2016.

OGI, Naoki. Ai no Muchi toiu Sakkaku. Taibatsu wa eskarêto shi, kosodate no chikara o ushinawaseru (A Ilusão do "chicote do amor": o castigo físico recrudesce e elimina a capacidade de criar os filhos). In: Nihon no Ronten 2007 - The Issues for Japan 2007, p. 616619. Tóquio: Bungei Shunju, 2006.

REKISHI KYOIKUSHA KYOGIKAI (Org.). Nihon Shakai no Rekishi Jô Genshi Kodai Kinsei (História da Sociedade Japonesa, vol. 1: Pré-história, Antiguidade a Pré-moderna). Tóquio: Otsuki Shoten, 2012.

SATO, M. et alii. Shôsetsu Nihonshi Kenkyû (Estudo detalhado da História do Japão). Tóquio: Yamakawa, 2008.

TAKAGI, Shingen. Kûkai-Shôgai to sono Shûhen (Kûkai: trajetória de vida e afins). Tóquio: Yoshikawa Kobunkan, 2009.

TOTSUKA, Hiroshi. Taibatsu ga Kodomo o Yomigaeraseru - seizensetsu ni motozuku waga yotto sukûru no tokuiku (O castigo físico ressuscita a criança: a educação da nossa escola de iatismo que se baseia no princípio da bondade dos humanos). In: Nihon no Ronten 2007 - The Issues for Japan 2007, p. 616-619. Tóquio: Bungei Shunju, 2006.

TSUCHIYA, Motonori. Gendaikyôikuseidoron (Teoria do Sistema Educacional Contemporâneo). Quioto: Minerva Shobo, 2011.

UZAWA, Hirofumi. Nihon no Kyôiku wo Kangaeru (Refletindo sobre a Educação do Japão). Tóquio: Iwanami Shoten, 1998.

WHANG, Soon Hee. Dôsôkai no Shakaigaku - Gakkôteki Shintai Bunka, Shinrai, Nettowâku (A Sociologia dos Encontros de Formados: a cultura corporal, confiança e rede das escolas). Quioto: Sekai Shisosha, 2007.

WOLFEREN, K. van. The Enigma of Japanese Power. Vol. 2. Tóquio: Hayakawa, 1990. 